\title{
A Conceptual Framework for Disruptive Innovation in Advising
}

\author{
Kay S. Hamada, MA \\ Assistant Specialist, Academic Advisor \\ University of Hawai ‘i at Mānoa \\ Email: kshamada@hawaii.edu
}

\begin{abstract}
Institutions of higher education seek innovative opportunities to keep up with changing student needs. Accordingly, frameworks such as Christensen's Disruptive Innovation theory may appear attractive on the surface to improve advising practices, but a deeper understanding of context and objectives is imperative to recognizing the applicability of such frameworks to practice. By clarifying what Disruptive Innovation is, and is not (i.e., sustaining innovation), it has been argued that the theory has been misunderstood and misapplied (Christensen et al., "What is Disruptive Innovation?"). A closer look reveals that in addition to benefits, the Disruptive Innovation framework also poses a number of challenges to advising. This study sets out to (1) clarify the theoretical framework of Disruptive Innovation and explore the relationship between Disruptive Innovation and advising; (2) examine the extent to which Disruptive Innovation theory can be applied in advising, via a case study; and (3) discuss the implications for Disruptive Innovation in advising.
\end{abstract}

\section{Introduction}

As the pace of communication and access to information becomes more rapid, institutions of higher education seek innovative opportunities to keep up with changing student needs, such as efficiency to degree completion and added availability of resources. While innovative frameworks address such needs, they can also challenge established theories and best practices. Accordingly, while an innovative framework may first appear attractive to improve advising practices, a deeper understanding of context and objectives is imperative to recognizing the applicability of such frameworks to practice. One example is Christensen's theory of Disruptive Innovation (DI). Shockley-Zalabak described DI as "[Christensen's] term for all of the changes that both stimulate crisis and innovation" (13). Addressing the future of academic advising, Shockley-Zalabak intersected DI with the concept of advising interaction design when stating, "I want academic advisors to think about being disruptive innovators as interaction designers" (13) and "Advisors are in a perfect position to lead disruptive innovation" (16). While Shockley-Zalabak makes a valid argument-designing advising interactions purposefully and with the intention of making a positive change in a student's educational experience can cause an exceptional shift in an advising system-for an innovation to truly follow a disruptive trajectory, it must include other restrictive traits, which consequently make the framework applicable to a selective scope of advising. Although advisors may use disruptive innovations, or develop responses to disruptive innovations, these innovative strategies are not always aligned with DI theory; thus, although the DI framework can present benefits, it also poses a number of challenges to advising, including the interdisciplinary use of the theory.

\section{Theoretical Background}

The theory of DI, which was foundationally used to examine and explain the success or failure of business startups, describes the process of how innovations (products or services) that are at first considered inferior to mainstream products/services eventually "disrupt" the dominant market as more people adopt the innovations (Christensen et al., Seeing What's Next; Christensen; Christensen and Eyring; Christensen et al., "What is Disruptive Innovation?"). Such innovations can be described as "simpler offerings" (Christensen et al., "Disruptive Innovation for Social Change"). Some principal characteristics of DI theory are

- Disruptive innovations initially target a niche or non-existent market that can benefit from products/services that are "good enough" to "get the 
job done" (Christensen et al., "What is Disruptive Innovation?”);

- The "jobs" of the consumer are used as the unit of analysis (Christensen); and

- Disruptive innovations "introduce a new value proposition" (Christensen et al., Seeing What's Next xvii) by redefining or creating markets that do not correspond to current trends or traditional ideals.

The fear of higher education moving away from relational values and heading toward transactional profits may lead to a stigma against entrepreneurial concepts; however, advisors also seek ways to change education by adapting and learning new, sometimes unconventional, systems. DI offers one possible lens. DI theory views disruption not as a single event or transaction, but the culmination of intentional interactions and ideas over time. Thus, this study does not propose that institutions be seen as a site of business, but, instead, as a site of potential disruption. At the core of DI theory is the focus on the consumer and acknowledging that products or services that currently exist do not work for everyone. The framework of DI involves examining established strategies and approaches to identify gaps. It also involves reorienting big picture outcomes to the more specific unit of "jobs" that are relevant to the individual (Christensen et al., Seeing What's Next). These traits of DI are parallel with advising philosophies-one size does not fit all; individual students have different motivations, learning styles, and paths to personal growth. Consequently, the framework can also disrupt long-standing best practices and challenge advising philosophies. An example of DI is community colleges: they offer undergraduate education without the selectivity and cost of 4-year schools due to their operating structures, they are a "good-enough alternative" for students' "initial needs," and provide access to higher education for those who may otherwise not have the opportunity (Christensen et al., "Disruptive Innovation for Social Change").

Christensen stated that in higher education, both institutional and student categories are "segmented" and using these segmented categories, "We do all sorts of correlations [...] The problem with this approach is that if you're a customer in the market, that's not how the world looks at all..." (45). Aca- demic advising also follows the "segmented" approach of focusing on targeted student populations (e.g., first-generation, academically at-risk, studentathlete, transfer). The DI framework asserts that this is problematic because these categories are not always a good fit with students' "jobs." For example, accessing academic advising services during regular business hours can be an issue for both nontraditional and traditional students. For nontraditional students, there may be obligations outside of school. For traditional students living on campus, there may be barriers such as being in classes and receiving supplemental instruction throughout the day. Academic advisors who create new advising programs cannot make assumptions about student needs based on such segments. Instead, a focus on the "job" (what students really need) is one step closer in understanding "how the world looks" from students' perspectives.

Further, the antecedents of the DI framework present traits that can be applied to academic advising, but which can also challenge current practices. For example, while advocates of technologyenhanced education argue that "sound pedagogy should drive the use of technology, and not the other way around" (Nicholson and Eva 500), the framework of DI infers that so-called sound pedagogy may be misdirecting efforts by lacking customized education and miscalculating "overshot" students (Christensen et al., Seeing What's Next). However, it would be inaccurate to say that the DI framework advocates a deficient pedagogy or is against pedagogy. Rather, DI indicates the discrepancy that while pedagogy is supposed to help a student learn in the best way possible, it has instead become restrictive, preventing students from learning "at their own pace, and in their own way" (Christensen and Eyring). For example, in an advising context, while current outcomes define expectations of student needs and how advising should address those needs, the framework of DI challenges these outcomes by asking whether they are overshooting students' "real" needs. The framework of DI, therefore, supports re-examining outcomes through a job-focused approach, to focus on specific settings that best address specific "jobs," which are not typically reflected in higher-level policies and outcomes of an institution (Christensen and Eyring). 
In a critique of DI theory, Lepore stated, "Ever since [Christensen's book] 'The Innovator's Dilemma,' everyone is either disrupting or being disrupted." Christensen et al. acknowledged the excessive use of the term when they stated, "Unfortunately, disruption theory is in danger of becoming a victim of its own success. Despite broad dissemination, the theory's core concepts have been widely misunderstood and its basic tenets frequently misapplied" ("What is Disruptive Innovation?" 46). To address this issue, DI theory further differentiates between disruptive and sustaining innovations.

Christensen et al. stated that innovations are not disruptive if they do not originate from one of two footholds: low-end and new-market. Whereas low-end foothold means "less demanding" and "less profitable" customers are provided with a "good enough" product, new-market foothold means that innovators "find a way to turn non-consumers into consumers" ("What is Disruptive Innovation?" 47). More often, the focus of advising interaction design is another type of innovation, called sustaining innovation, defined as making "good products better in the eyes of an incumbent's existing customers" (Christensen et al., "What is Disruptive Innovation?" 47).

Notably, some innovations can be both sustaining and disruptive, depending on the scope of a case study. Just as Gerring stated, "shifts in the unit of analysis of a proposition change the referential meaning of all terms in the semantic field" (342). Although Christensen et al. stated, "Disruption is a relative concept. The same innovation can look different to different companies" (Seeing What's Next 106), innovations at traditional campus-based universities tend to be grouped into a non-disruptive category. For example, taking a cue from previous case studies in higher education (e.g., Christensen and Eyring; Powell et al.), if implementing an innovative advising program is examined from an institutional level, defining the student population as high-end customers who are in need of academic advising, any advising program would be considered a sustaining innovation by default because it is working within the university's current model, which includes a stable academic calendar according to which courses are attended, and paying tuition according to the university's set tuition table. In this context, because advising targets an existing high- end market (students), an innovative program, such as online advising through videoconferencing, can be a response to DI (the availability of online learning tools), with the goal of improving services that are already being used. Yet, because academic advising strategies and practices are not always consistent throughout a campus, a case study at the institutional level may not be appropriate. The following hypothetical scenarios provide examples of advising that fit both sustaining and disruptive innovations at one institution.

Scenario One: Sustaining Innovation. An academic advising unit (AAU) requires students to meet with an advisor every semester by implementing mandatory advising holds. A few students complained that they are unable to meet with advisors because they are either in class or working during office hours and do not have time to travel back and forth from their work site during their breaks; consequently, they are forced to skip class, which impacts their learning, or decrease their work hours for the week, which impacts their finances, to avoid the hold. However, the AAU prefers to talk with students in person rather than over the phone, because it values advantages of face-to-face interaction such as seeing facial expressions which contributes to a sense of personal connection. As a compromise, the AAU decides to offer advising via videoconferencing software, so that students are not required to travel to campus to meet with an advisor, yet elements of face-to-face interaction are available through the platform. The AAU also changes the duration of advising meetings from 30 minutes, to giving an option of 15 minutes or 30 minutes, so students can meet during break times (including breaks between class). This is an example of sustaining innovation because it targets a population of students who already use advising, the AAU works within the current advising structure (e.g., during office hours), and the "job" of fulfilling mandatory advising remains.

Scenario Two: Disruptive Innovation. Another AAU does not require students to meet with an advisor every semester, although advisors regularly call and email students with invitations to advising. The AAU's data shows an increasing number of students who never see an advisor there. In a survey asking students why they have not met with the AAU, responses show students are in class or at work during AAU office hours, don't have time to sit down for a 
conversation with an advisor, must wait several days to book an appointment, and feel intimidated approaching an authority figure in person. As a result, students seek advice from more readily available sources that may not provide correct or complete information. The AAU decides that to reach these nonuse students, it needs to offer longer hours of availability, more instant access to advisors to answer questions quickly and efficiently, and a wider range of communication methods. However, faced with budget cuts, the AAU cannot hire more advisors to increase availability. During a meeting with administration regarding shortage of space on campus, the AAU sees an opportunity: the AAU agrees to release its office space, in exchange for funds to hire additional advisors and a dedicated IT person, committing resources toward creating an "advising center" that is completely online. The advisors are trained to use online platforms and work from home. Appointments are replaced with a first come, first served system, and advisors' online hours extend beyond regular business hours. Students can personalize their communication experience by choosing phone, email, chat, videoconferencing, or a homegrown electronic advisor chat bot that is always available to answer simple questions. This example aligns with the DI framework because it targets a population of nonconsumers (students who are not meeting with AAU advisors); changes the advising structure (advising completely online with "simpler offerings"); and addresses "real competitors" (lack of time and access to advisors, inconvenience, feeling intimidated, other readily available sources of advice).

As illustrated in these scenarios, the goals of sustaining and disruptive innovations differ. With the first AAU, an online advising program was implemented to provide more access to advising for the existing population of students using advising. Conversely, in the second AAU, online advising was implemented to increase the number of students seeking advising, targeting students who do not use advising. Further, the goals of sustaining and disruptive innovations can inform and clarify expectations (Christensen and Eyring). In the context of a sustaining innovation, expectations center on usage; an uptick in adoption within the existing population, therefore, does not appear to make a significant impact on the overall model (e.g., "five percent of our students use the online advising program"). On the other hand, in the context of a disruptive innovation, the focus is on market growth; when a minority market experiences growth, even in small increments, that growth is noteworthy (e.g., "the number of students using advising has risen five percent since implementing our online program"). As a result, if sustaining and disruptive innovations are not correctly differentiated, then an AAU will have misinformed expectations of benefits.

In the context of higher education, jobs can vary depending on the individual student and his or her life situation; as Christensen et al. stated, while "to learn" is a broad-level "job" that pertains to all students, there are more proximal "jobs" that students are trying to accomplish, such as "Get me a job," "“Help me solve a problem,"” and "'Brand me in a way that enhances my long-term career potential." (Seeing What's Next 102). Additionally, jobs represent emergent needs, inclusive of "hidden needs" (Choy and Park) that students are not aware they need to accomplish or do not disclose. Examples can include school-life balance (e.g., realizing they need to drop courses), identifying new opportunities and resources (e.g., workshops, events, and newly announced scholarships), and clarifying life goals (e.g., realizing they want a different major). Emergent needs also include changes in goals that can occur through the student-advisor interaction. Identifying student "jobs" further clarifies the "real competitors" of advising, such as other advising technologies and information resources (including informal "advising" by friends), not knowing why they should see an advisor or what they can gain from advising, in addition to feelings like overconfidence or a false sense of competency (e.g., as described in Kruger and Dunning) and intimidation.

\section{Case Study}

Method. The following case study was chosen because it illustrates the incorporation of advising services in a program that demonstrates DI concepts. The case study method is used because it can examine "complex issues that are not yet well grounded in theory and on which there is limited evidence and understanding" (Hang et al. 85). Gerring proposed the following definition of the case study: "an intensive study of a single unit for the purpose of understanding a larger class of (similar) units" (342). Qualitative data was collected through secondary sources (conference presentation, program 
website) and an interview with the program coordinator, to establish case history and gain insight into the program's current standing. The aim of this analysis is to compare the features of DI theory from the literature to practice, to interpret possible application of the framework.

$C B M$. Established in 2014, the University of Hawai'i at Mānoa’s Come Back to Mānoa (CBM) program is an outreach program, conducted by UH Mānoa's extension Outreach College division, which "supports undergraduate seniors who left UH Mānoa to return and graduate" by identifying the target market of students who had earned 90 or more credits, earned a 2.0 or higher Mānoa GPA, and had not enrolled at UH Mānoa for at least two semesters (Johnson). The program was proposed due to the concern that a significant number of seniors were leaving the university without completing their degree (Johnson); thus, aligned with this concept, the goals of the program are to support students in "completing their degree for the many personal benefits of having a bachelor's degree" and "to increase institutional graduation numbers" (University of Hawai'i at Mānoa Outreach College). As part of the outreach process, the program coordinator identifies candidates as "eligibles" (those who can graduate without additional coursework) and "potentials" (those who require courses to graduate), contacts candidates, and advises them according to their individual case (Johnson).

The CBM program fits into the framework of DI because it originates from footholds: both lowend - a population that is not applicable to institutional graduation rates - and nonconsuming because they have not continued their education at UH Mānoa; as some students have attested, they would not have earned their degree without the program (Johnson). Additionally, the program is job-focused: while an immediate "job" relevant to all students is to complete a UH Mānoa degree, further jobs are based on accomplishing goals including obtaining personal benefits (occupational; economic), and satisfying intrinsic motivation (addressing "regret"; "set a good example to the future generations") (Johnson).

One approach to accomplishing students "jobs" is to find what barriers prevent them from accomplishing their jobs and removing those barriers.
Choy and Park proposed identifying "hassles" experienced by consumers, stating, "finding a way to reduce or remove hassles occurring in consumers' lives causes the beginning of the creation of attractive products" (9). The authors named hassles in three essential categories: waste (e.g., "money and time"), inconvenience (e.g., "complicated processes, difficult usage, and inefficiency"), and anxiety (e.g., "psychological and physical" anxiety) (9). For CBM, data provided by a "Leaver's Report" identified what can be categorized as "hassles": reasons students stopped out or dropped out, including personal ("health concerns"; employment opportunity), financial (high cost of living; high tuition and fees), insufficient support services ("inadequate academic advising"; "felt uncared about") and academic ("classes were not convenient"; underprepared for college-level work) (Johnson). In identifying past issues, the program also identifies "real competitors" that may keep students from finishing their degree upon their return. While students who are not close to graduation eventually return into established advising models with their college and major advisors, which is characteristic of a sustaining innovation, students who are either "eligibles" or "potentials" close to graduation are a niche group that experience advising in a DI framework. For example, when students are unable to attend courses in person, although the coordinator first looks at UH Mānoa course options, in some cases required courses are only offered in person at UH Mānoa. In these situations, the program coordinator acts as an advocate for the student by researching and assisting in availing possible alternatives. In one such case, the coordinator worked with a major advisor who specially created a directed reading and research course that covered the curriculum of the required class, but that allowed the student to work at a distance without having to attend class on campus. In another situation where an online course was not available through the university, the program coordinator referred students to an online course offered through another institution, that was transferrable to $\mathrm{UH}$ Mānoa to meet a needed graduation requirement (Johnson, Personal interview). This matches the framework of DI because the curriculum does not fit into the institution's traditional course structure, giving students a flexible and convenient way to complete their degrees. 
Additionally, for students who are close to graduation, those who are no longer on island, or who work full-time during the university's business hours, may be unable to travel to campus to meet with the program coordinator in person. Some students may also meet only with the coordinator as an intermediary rather than directly with their major or college advisors (Johnson, Personal interview). The advising they receive, therefore, does not fit into the institution's regular advising framework, and models such as developmental or liberal arts advising may not be practiced with these students; this niche advising model fits into the DI framework, because established advising models would "overshoot" the needs of students. As an example, Johnson stated,

I work closely with college/major advisors across campus to clarify any questions I have or to advocate on behalf of a student. Depending on the academic college, I often will fill out a student's graduation paperwork and send it to them for review and signature, and then I'll walk the paperwork around campus to obtain necessary major/minor advisor signatures and deliver it to the college for review and processing. I view this as trying to reduce barriers to graduation, especially since a number of my students don't live in Hawai 'i anymore or work full time and can't run forms around campus. (Personal interview)

Because CBM students are earning their degrees for specific personal reasons, and because their experience, age, and life situation differ from traditional students, they may consider paradigmatic advising methods as not conducive, or the time such methods would require a barrier, to fulfilling their "job"-in such cases, expediency can take precedence over exploration. Further research into the program can examine whether advising in the traditional college units is impacted by CBM.

Moreover, although videoconferencing is available, students who do not meet the program coordinator in person typically choose to hold advising meetings by phone. The program coordinator stated that such communication methods do not detract from the advising session because she is able to convey the information that students need, while also using alternative instructional methods such as having the student navigate online resources on their personal computer during the conversation (Johnson, Personal interview). Therefore, this advising context is not consistent with concerns about lack of nonverbal communication, because, in line with the DI framework, technology-mediated communication is "good enough" for these students. These examples further illustrate the concept of job-focused outcomes, as in these cases obtaining the information to start their return to UH Mānoa is the focus of CBM students.

Just as Powell et al. pointed out, DI theory "predicts that disruptive innovations, when proposed internally, will almost always be rejected by an incumbent organisation, even when it is clear that an external disruptive innovator is beginning to attack the low end of their existing market" (11). Accordingly, it is suggested that innovators work independently from those serving high end customers, being designated to plan, implement, and market the potential disruptive innovation with relative autonomy (Assink; Powell et al.). CBM parallels this DI model because the program is housed in the UH Mānoa Outreach College, rather than in the traditional colleges. Consequently, although part of a single campus' student services system meeting institutional demands, and working in partnership with the colleges, the Outreach College runs programs with its own staff, marketing, and operations (e.g., admissions, tuition, registration). The Outreach College, therefore, benefits from relative dichotomy (having a degree of separation from the traditional college or major structures), while obtaining support from university administration. Yet, also fitting of the DI model is the challenge of needing additional resources-with a growing caseload, upcoming discussions of increasing staff and funding for the program can impact its quality and outlook (Johnson, Personal interview).

Although the niche advising components of CBM correspond with the DI framework, there are certainly limitations-for example, exceptions are not always available to students. However, the program has disruptive opportunity wherein a student's curriculum can increasingly become tailored to the individual and students are able to patchwork their coursework from institutions, or different sets of requirements, to earn a degree. Notably, the program illustrates the reframing of outcomes that is charac- 
teristic of DI: this can be represented as the questions "What 'job' is the student really trying to accomplish?" and "Are we helping them to accomplish their "job'?"

\section{Discussion}

Although examples of disruptive innovations on a traditional university campus may be limited, this study examines the potential for the framework to be applied, as demonstrated in the presented case. Whereas a more clarified definition of the theory places emphasis on the DI framework as restricted to specific conditions and outcomes, the current research agrees that advisors can be disruptive innovators to an extent while highlighting the importance of understanding the foundations of the theory, its benefits and challenges, and its limitations.

Despite the DI framework's focus on consumers and giving them something "good enough," it should be noted that balance needs to be attained with giving students the choice to give up something they don't really need (e.g., being in the same physical space as the advisor) while also avoiding forgoing something that they need but of which they are unaware. Therefore, the approach of identifying "hidden needs" (Choy and Park) is crucial in considering students" "jobs" - it is not just a business strategy to sell more of an advising service, but to also make sure the student is getting what is imperative to their success. In DI, the issue of compromise is eminent. For example, in the scenario of an AAU going completely online, there is a risk of losing existing users who prefer in person contact or have phobias about online contact. Further, if the AAU in this situation wants to include a more extensive relational component, it would need to consider how to unbundle this from advising meetings. There is also the question of how other stakeholders on campus will be affected by the changes; who will students talk to on campus if the AAU does not have a physical office? Will faculty know how advising works? On the other hand, when DI concepts such as job-focused outcomes and "real competitors" are applied to academic advising, it is apparent that traits of interpersonal communication that may appear to enrich the interaction can also present a barrier for some students. Consequently, while some students and advisors need inperson interactions and would prefer meeting in the same physical space (see Joslin; Taylor et al.;
Noonan and Stapley), other students may prefer technology mediated communication, which includes behavioral changes and potential pedagogical changes due to missing information on which advisors might typically rely. Accordingly, one aspect of the DI framework that can help transform advising is the potential benefit to students who do not feel comfortable with in-person interactions, including students who are shy or are introverted.

Shockley-Zalabak stated that the "role of the academic advisor is changing," being affected by trends such as globalization, instant communication, diverse populations, and financial pressures (13). While not all innovations created to address these equations are disruptive, these are factors that drive the creation of disruptive innovations because they force advisors to examine existing structures critically and to explore the unfamiliar to find what can further impact student engagement. In the framework of DI, advisors will be required to reassess and potentially reformulate approaches, such as defining student populations, and outcomes, which includes reframing of tasks, that are prevalent in advising.

\section{References}

Assink, Marnix. "Inhibitors of Disruptive Innovation Capability: A Conceptual Model. European Journal of Innovation Management, vol. 9, no. 2, 2006, pp. 215-233.

Choy, Minkyung, and Gunno Park. "Sustaining Innovative Success: A Case Study on Consumer-Centric Innovation in the ICT Industry." Sustainability, vol. 8, no. 10, 2016.

Christensen, Clayton. "Disruptive Innovation and Catalytic Change in Higher Education." Forum for the Future of Higher Education, 2008.

Christensen, Clayton M., Scott D. Anthony, and Erik A. Roth. Seeing What's Next: Using the Theories of Innovation to Predict Industry Change. Harvard Business School Press, 2004.

Christensen, Clayton M., Heiner Baumann, Rudy Ruggles, and Thomas M. Sadtler. "Disruptive Innovation for Social Change." Harvard Business Review, Dec. 2006,

Christensen, Clayton M., and Henry J. Eyring. The Innovative University: Changing the DNA 
of Higher Education from the Inside Out. Jossey-Bass, 2011.

Christensen, Clayton M., Michael E. Raynor, and Rory McDonald. "What is Disruptive Innovation?” Harvard Business Review, Dec. 2015, pp. 44-53.

Gerring, John. (2004). "What Is a Case Study and What Is It Good For?" American Political Science Review, vol. 98, no. 2, 2004, pp. 341354.

Hang, Chang C., Elizabeth Garnsey, and Yi Ruan. "Opportunities for Disruption." Technovation, vols. 39-40, 2015, pp. 83-93.

Johnson, Shannon. "Why Seniors Leave and How to Help Them Graduate." Council of Academic Advisors Conference, 27 July 2017, University of Hawai'i at Mānoa, Honolulu, HI. Conference presentation.

---. Personal interview. 1 October 2017.

Joslin, Jennifer. "Voices from the Field: Veteran Advisors." NACADA Journal, vol. 29, no. 2, 2009, pp. 68-75.

Kruger, Justin, and David Dunning. "Unskilled and Unaware of It: How Difficulties in Recognizing One's Own Incompetence Lead to Inflated Self-Assessments." Journal of Personality and Social Psychology, vol. 77, no. 6, 1999, pp. 1121-1134.

Lepore, Jill. "The Disruption Machine: What the Gospel of Innovation Gets Wrong." The New Yorker, 23 June 2014.

Nicholson, Heather, and Nicole Eva. "Information Literacy Instruction for Satellite University Students." Reference Services Review, vol. 39, no. 3, 2011, pp. 497-513.

Noonan, Jennifer., and Janice C. Stapley. "The Demise of In-Person Academic Advising is Nowhere in Sight! Academic Advising Today, vol. 38, no. 1, March 2015.

Powell, Stephen, Bill Olivier, and Li Yuan. "Handling Disruptive Innovations in HE: Lessons From Two Contrasting Case Studies." Research in Learning Technology, vol. 23, no. 1, 2015.

Shockley-Zalabak, Pamela. (2012). "Advisors as Interaction Designers." NACADA Journal, vol. 32, no. 1, 2012, pp. 12-17.

Taylor, Melissa, Doreen Jowi, Howard Schreier, and Dale Bertelsen. "Students' Perceptions of EMail Interaction During Student-Professor
Advising Sessions: The Pursuit of Interpersonal Goals." Journal of Computer-Mediated Communication, vol. 16, no. 2, 2011. University of Hawai' $i$ at Mānoa Outreach College. "About Come Back to Mānoa." Come Back to Mānoa. 